\title{
Determination of metals in humic acid salts by ICP-AES
}

Karpukhina E.A., Vlasova E.A., Volkov D.S., Proskurnin M.A., Perminova I.V. Lomonosov Moscow State University, Moscow, Russia, karpukhina.evgeniya@gmail.com doi: 10.36291/HIT.2019.karpukhina.031

Humic substances (HS) consist of heterogeneous, difficult to separate mixtures of closely related organic macromolecules with a wide molecular weight distribution and a rich variety of functional groups. Due to many ways they interact with organic and inorganic substances in the environment, HS are of great importance for the biosphere. In particular, the high complexing ability of HS with metal ions has a significant effect on transport, deposition, and the presence of heavy metals in soils and water systems.

As humic substances are widely used as fertilizers in agriculture, the ability to determine the amount of heavy metals associated with HS in commercial samples is of great importance for predicting and accurately assessing the amount of certain metals introduced into the soil, as it is necessary to be able to evaluate both the toxic properties of the fertilizer and its nutritional properties. For example, humates of coal origins often contain arsenic, which is contained in the feedstock.

The best method for determining the metal content in humic samples is atomic emission spectroscopy with inductively coupled plasma (ICP-AES). It is widely used in biological, medical, and environmental studies, in particular for the determination of metals in waters, soils, and other natural materials. ICP-AES is a highly sensitive method, provides the results with high accuracy in the range from ultralow to macroscopic amounts, and simultaneously determines more than 70 elements.

As the objects of study, the salts of "Life Force" (sodium humate, Russia), "Sakhalin" (potassium humate, Russia) and "Powhumus" (potassium humate, Germany) humic acids were selected. An ICP-AES Agilent 720ES spectrometer with axial plasma view was used.

The following methods for the decomposition of humates were selected: direct introduction of aqueous solutions with and without preliminary centrifugation, nitric acid extract, fusion with lithium metaborate, and microwave decomposition with nitric acid. The following metals were determined: $\mathrm{Ag}, \mathrm{Al}, \mathrm{As}, \mathrm{B}, \mathrm{Ba}, \mathrm{Be}, \mathrm{Ca}, \mathrm{Cd}, \mathrm{Co}, \mathrm{Cr}, \mathrm{Cu}, \mathrm{Fe}, \mathrm{K}, \mathrm{Li}, \mathrm{Mg}$, $\mathrm{Mn}, \mathrm{Mo}, \mathrm{Na}, \mathrm{Ni}, \mathrm{P}, \mathrm{Pb}, \mathrm{S}, \mathrm{Sb}, \mathrm{Se}, \mathrm{Si}, \mathrm{Sn}, \mathrm{Sr}, \mathrm{Ti}, \mathrm{V}, \mathrm{W}$, and Zn.

The study of humic preparations of coal origin using ICP-AES showed that all the studied samples have the same elemental composition and differ in the ratio of components: in Powhumus S, Ti, Li, Cr and As prevail; in Sakhalin, Sr, Ba, Co , W and Cu. The content of microimpurities was calculated in the samples (Sakhalin, about 1440 $\mathrm{mg} / \mathrm{kg}$; Powhumus, about $470 \mathrm{mg} / \mathrm{kg}$; and Life Force, about $290 \mathrm{mg} / \mathrm{kg}$ ) and macroimpurities excluding potassium and sodium (Sakhalin, about $450 \mathrm{~g} / \mathrm{kg}$, of which 350 $\mathrm{g} / \mathrm{kg}$ is silicon; "Powhumus" is about $360 \mathrm{~g} / \mathrm{kg}$, of which $315 \mathrm{~g} / \mathrm{kg}$ is silicon; and the Life Force is about $163 \mathrm{~g} / \mathrm{kg}$, of which $142 \mathrm{~g} / \mathrm{kg}$ is silicon).

Comparison of decomposition methods showed that the most complete extraction of elements (except $\mathrm{Cd}, \mathrm{As}$, and $\mathrm{S}$ ) occurs by fusion with lithium metaborate. For $\mathrm{Ca}, \mathrm{S}, \mathrm{Ni}$, and $\mathrm{Be}$, sample preparation method was not of great importance; for other decomposition methods, the content of elements increased in the series of an aqueous solution - nitric acid decomposition - fusion.

If necessary, rapid assessment of the metal content in humic samples can be limited to the analysis of aqueous extracts without subsequent centrifugation. 